\title{
scripted
}

Volume 14, Issue 2, December 2017

\section{Book review: Revisiting the Regulation of Human Fertilisation and Embryology}

\author{
Kirsty Horsey (ed.) \\ Oxon: Routledge, 2015. 219 pages. ISBN 9781138021891. £38. \\ Reviewed by Catriona McMillan* \\ (ㄷ) (1) $\circledast \Theta$ \\ (C) 2017 Catriona McMillan \\ Licensed under a Creative Commons Attribution-NonCommercial- \\ NoDerivatives 4.0 International (CC BY-NC-ND 4.0) license
}

DOI: 10.2966/scrip.140217.358

\footnotetext{
* PhD candidate, School of Law, University of Edinburgh, c.mcmillan@ed.ac.uk
} 
Revisiting the Regulation of Human Fertilisation and Embryology asks an increasingly iterated question in the field of human reproductive law and ethics: has the Human Fertilisation and Embryology Act 2008 ("the 2008 Act") achieved its stated aim of being "fit for purpose"? It asks and responds to this question in a series of contributions from leading international authors, ${ }^{1}$ who critically explore some of the novel challenges and risks that have emerged in light of human fertilisation and embryology technologies and techniques, both new and old. ${ }^{2}$ Each chapter in this book addresses a key topic from the field, including: preimplantation genetic diagnosis ("PGD"); sex selection; compensating reproductive harms, and surrogacy in the UK. These explorations are not limited to UK law only, with some chapters looking at Canadian or Australian law (both of which have substantial similarities to the UK's legal framework).

The series of contributions opens with a chapter by the book's editor, Kirsty Horsey (University of Kent), who articulates the aims of the book and gives a brief and effective analytical overview of the development of the regulation of human fertilisation and embryology in the UK. As she states:

This book represents a snapshot of opinions on various aspects of the 2008 Act and comparative legislation, analysing and considering whether its provisions go far enough (or even too far) and meet the aim of bringing and keeping the law up to date. (p. 6)

1 Many of the book's contributors also contributed to a similar, earlier collection that is part of the same series. See Kirsty Horsey and Hazel Biggs (eds.), Human Fertilisation and Embryology: Reproducing Regulation (Oxon: Routledge-Cavendish, 2007).

2 The book was published as part of a series, Biomedical Law and Ethics Library (edited by Sheila AM McLean), which analyses the legal and ethical questions raised by recent developments in science, healthcare, politics, and society. 
Here she also provides an overview of each chapter, and each of the topics discussed in the volume, which serves as a useful introduction, especially for the uninitiated reader.

Eric Blyth (University of Huddersfield) considers the first theme of the collection, the revised "“welfare of the child" clause within the 2008 Act. Blyth provides a comprehensive review of key sources of review and reform on this matter, which stemmed from initiatives by Parliament, government and regulatory bodies, including House of Commons Science and Technology Committee inquiry and Human Fertilisation and Embryology Authority consultation. He concludes by combining his review with evidence from empirical studies, and emphasises that one must ask whether this change in wording has caused any practical shift in parental or professional behaviour. As he queries: "what was the point?" (p. 26). In doing so, Blyth effectively highlights the seemingly purely symbolic effect of this change in wording.

In Chapter 3, Emily Jackson (LSE) then considers the relatively modern and understudied phenomenon of "DIY assisted conception". Here, she assesses both the law's failure to regulate private arrangements ${ }^{3}$ and the dangers that these pose for individuals. Positing that DIY assisted conception now coexists with strictly regulated fertility treatments in the UK, she considers whether this "regulatory vacuum" (p. 31) within the framework indeed matters. In order to answer this, Jackson gives a detailed overview of the regulatory gaps and case law in this area, highlighting the complications for this phenomenon arising as result of surrogacy, cross-border reproductive treatment and "internet-assisted conception" (p. 39). She concludes by emphasising that we require information

3 Where a man provides sperm for a woman who wishes to self-inseminate, a practice that has increased dramatically because of the internet. 
about the risks of unregulated treatment (and the benefits of regulated treatment) to be made more widely available.

In Chapter 4, Helen Codd (University of Central Lancashire) discusses prisoner access to fertility treatments. She analyses two key cases on this topic $\left(\right.$ Dickson $^{4}$ and $\left.M e l l o r 5\right)$, and assesses their impact on prisoners' rights. In doing so, she highlights the different issues and challenges that arise when prisoners and their partners seek access to fertility treatment services in the UK.

Karen Devine (University of Kent) considers an alternative approach to fertility treatments, "benefits in kind," in Chapter 5 . Here she points out that the process of egg sharing ${ }^{6}$ can leave non-affluent women in a disadvantaged position, and proposes a solution whereby women use and exchange a different biological material, namely umbilical cord blood stem cells. For Devine, replacing this with the use and exchange of eggs would not only lead to more equal access to fertility treatment services, but also increase the bank of umbilical cord blood stem cells, which is a much-needed medical resource. She accepts that her proposal is "not a perfect model" (p. 77), but argues that the potential benefits make it worthy of serious consideration.

Revisiting the Regulation of Human Fertilisation and Embryology is apt in its study of legal and ethical controversies under the HFE Act, old and new. In Chapter 6, Jeanne Snelling and Colin Gavaghan (both University of Otago) evaluate whether the 2008 Act is "fit for purpose" as per its regulation of PGD. They suggest not only that the amendments failed add any "clarity, or consistency" (p. 80) to the matter, but also that the Act left the key question of the extent of the legitimacy of the state's role in regulating reproduction

4 Dickson and Another v United Kingdom (2008) 46 EHRR 41.

5 The Queen on the Application of Mellor v Secretary of State for the Home Department [2001] 3 WLR 533.

6 Often-controversial schemes that have been around for some time. 
unaddressed. The subject of Chapter 7 is an equally controversial topic; the new regulation of mitochondrial donation in the UK is particularly topical. Laura Riley (Genomics England) provides an overview of some of the ethical and legal issues arising from regulation of this relatively new technique, which, at the time of writing, was about to be voted on in Parliament.

In Chapter 8, Kirsty Horsey and Katia Neofytou (University of Kent) consider the UK's regulatory approach to surrogacy, a treatment often forgotten in the midst of the new technologies of recent years. After providing a brief overview of surrogacy law in the UK, they assess what they label as "twenty-first Century surrogacy problems" (p. 117), which they argue have stemmed from both globalisation, and the inertia of UK regulation with respect to surrogacy. Finally, they explore models of surrogacy regulation in Greece and Israel, noting the lessons that UK law could learn from them. Their exploration concludes with a convincing call for reform in this area, noting the benefits to safety and fairness this may bring.

In Chapter 9, Eric Blyth and Lucy Frith (University of Liverpool) discuss national regulatory regimes that "actively facilitate" (p. 137) those born from donor conception to trace the identity of his/her donor. They provide an outline of the legal frameworks in each of the 11 jurisdictions examined, which, by their own admission, preclude them from providing detailed discussion of these due to space. This summary is nonetheless quite comprehensive, and highlights the change in trend (internationally) toward the "opening up of gamete donation" (p. 149).

Antony Blackburn-Starza (University of Kent) then provides a rather philosophical examination of compensation for reproductive harms in the context of modern assisted conception. Here he provides an outline of, what he suggests is, the law's failure to provide a characterisation of harms arising from errors in the provision of assisted reproductive services in the UK. He posits that 
this failure not only is in tension with the underpinning aims implied in the 2008 Act (i.e. recognition of the family and reproductive autonomy), but also falls "out of step" with modern trends in bioethical and legal scholarship. He thus makes an interesting case for the legal recognition of harm in this area by considering how a normative framework might be constructed.

The book then proceeds to discuss the international legal dimensions of human fertilisation and embryology. In Chapter 11, Pamela White (University of Kent) reviews Canada's Assisted Human Reproduction Act 2004 and its position after a key decision by Canada's Supreme Court in 2010. Looking at possibilities for the future in this area for Canada, she recommends the government revisit a number of aspects of the law, including the "criminal regime imposed by the Act" (p. 181), and the establishment of a central authority (similar to the UK's HFEA). Mirroring Snelling and Gavaghan's discussion in Chapter 6, in Chapter 12, Isabel Karpin (UoT Sydney) compares the PGD regulatory models of Australia and the UK. Here she critically assess forms of sex selection (to avoid the birth of a child with a "sex of gender related disorder") (p. 186) currently legal in both countries. In doing so, Karpin highlights medical sex selection as an example of gendered assumptions behind our framings of disability and notions of harm in the regulation of new technologies. The final contribution, in Chapter 13, also considers the jurisdictions of Australia and the UK. Anita Stuhmcke (UoT Sydney) considers both countries' judicial responses to international commercial surrogacy. By way of comparative analysis, she suggests that the law pertaining to surrogacy in both countries require urgent reform.

Overall, this edited collection provides a timely and effective overview and analysis on a wide range of legal and ethical issues pertaining to the amendments made by the 2008 Act. My one quibble is that it would have benefitted from a concluding chapter to draw threads between each chapter per the aim of the collection articulated in Chapter 1. Despite this, it is a thoughtfully 
put together set of chapters on some of the key issues arising out of the 2008 amendments, each managing to be concise without lacking in detail or depth of analysis. It is therefore recommended to be of use and interest to medical law academics and practitioners alike. 